\title{
Toward an Understanding of Ion Transport through the Na,K-ATPase
}

\author{
HANS-JÜRGEN APELL \\ Department of Biology, University of Konstanz, Fach M635, 78457 Konstanz, Germany
}

\begin{abstract}
In the Na,K-ATPase the charge-translocating reaction steps were found to be binding of the third $\mathrm{Na}^{+}$ion to the cytoplasmic side and the release of all three $\mathrm{Na}^{+}$ions to the extracellular side as well as binding of the two $\mathrm{K}^{+}$ ions on the extracellular side. The conformation transition $E_{1} \rightarrow E_{2}$ was only of minor electrogenicity; all other reaction steps produced no significant charge movements. In the SR Ca-ATPase and the gastric H,K-ATPase, all ionbinding and -release steps were identified to move charge through the membrane. The high-resolution structure of the SR Ca-ATPase in state $\mathrm{E}_{1}$ revealed the position of the ion-binding sites in the transmembrane part of the protein. If the same arrangement is assumed for the Na pump, the missing expected charge movements in state $E_{1}$ may to be assumed to be apparent effects. With the proposal that binding of $2 \mathrm{Na}^{+}$or $2 \mathrm{~K}^{+}$is compensated correspondingly by $\mathrm{H}^{+}$ions, agreement between structural and functional aspects is obtained. Investigations of the $\mathrm{pH}$-dependence of ion-binding steps indicate competition between the ions and electrogenic $\mathrm{H}^{+}$binding in support of this concept.
\end{abstract}

KEYWORDS: binding sites; ion transport; pH effects; electrogenicity; styryl dyes; fluorescence; competitive inhibition of ion binding

\section{INTRODUCTION}

The function of the Na,K-ATPase in the membrane of cells maintains the electrochemical potential gradient of $\mathrm{Na}^{+}$and $\mathrm{K}^{+}$ions. ${ }^{1-3}$ Ion transport is facilitated by coupling the energy-providing enzymatic process with a ping-pong mechanism of ion translocation. ${ }^{4}$ This process is described by the so-called post-Albers cycle ${ }^{5,6}$ (FIG. 1A). If, for example, the $\mathrm{Na}^{+}$translocating pathway of the cycle is examined, we see that four reaction steps could contribute to the charge translocation: (1) ion binding; (2) ion occlusion; (3) conformation transition; and (4) ion release to the opposite side (FIG. 1B). To quantify the "dielectric" distance over which the ion is moved, dielectric coefficients were introduced that describe the fraction of the membrane dielectric over which the charge is shifted perpendicular to the plane of the membrane. ${ }^{3}$ If the dielectric coefficient is non-zero, the accompanying reaction is termed "electrogenic." In FIGURE 1B the dielectric coefficient for cytoplasmic binding of a $\mathrm{Na}^{+}$ion would be $\alpha^{\prime}$ (and $\alpha^{\prime}+\beta^{\prime}+\beta^{\prime \prime}+\alpha^{\prime \prime}=1$ for the transfer across the whole membrane). In the last decade numerous studies were performed with differ-

Address for correspondence: Hans-Jürgen Apell, Department of Biology, University of Konstanz, Fach M635, 78457 Konstanz, Germany. Voice: +49-7531-882253; fax: +49-7531-883183.

h-j.apell@uni-konstanz.de 
A

B

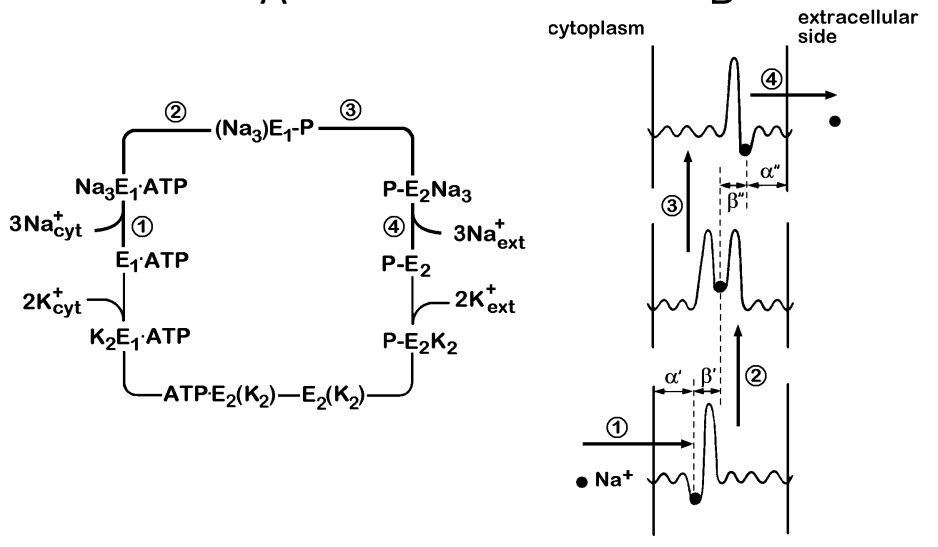

FIGURE 1. (A) Post-Albers cycle of the $\mathrm{Na}, \mathrm{K}-\mathrm{ATPa} e$. The $\mathrm{Na}^{+}$-translocating pathway is characterized by four partial reactions: (1) $\mathrm{Na}^{+}$binding; (2) ion occlusion and enzyme phosphorylation; (3) conformation transition $\mathrm{E}_{1} \rightarrow \mathrm{E}_{2}$; and (4) $\mathrm{Na}^{+}$deocclusion and release. (B) Schematic representation of the energy profile of the $\mathrm{Na}^{+}$pathway for the various states of $\mathrm{Na}^{+}$translocation. The Greek letters indicate the corresponding dielectric coefficients (see text).

ent electrophysiological and fluorescence spectroscopical techniques to determine the dielectric coefficients of all electrogenic partial reactions. ${ }^{7-10}$

On the basis of these results, a structure-function concept was constructed in which on the extracellular side, the first $\mathrm{Na}^{+}$ion is released through a narrow access channel, the step with the highest dielectric coefficient $\left(\alpha^{\prime \prime} \approx 0.7\right) ; 7,8$ then a conformational relaxation occurs ${ }^{11}$ before the other two $\mathrm{Na}^{+}$ions reach the aqueous phase with lower dielectric coefficients $(0.1-0.2)$, probably caused by reduction of the dielectric coefficient of the transmembrane part of the pump protein, for example, by intrusion of water molecules. ${ }^{7}$ On the cytoplasmic side only a single reaction step was detected to be electrogenic, binding of the third $\mathrm{Na}^{+}$ion. ${ }^{12,13}$

When similar studies of the electrogenicity were performed with the SR CaATPase $^{14,15}$ and the gastric H,K-ATPase (unpublished data), it was found that in these P-type ATPases all ion-binding and -release reactions were electrogenic. This difference from the $\mathrm{Na}, \mathrm{K}$-ATPase is significant, since all three ATPases are believed to have closely related structures. ${ }^{16}$ An important input into the considerations of structure-function relations was produced by the 3-D structure of the $\mathrm{E}_{1}$ conformation of the SR Ca-ATPase at atomic resolution, ${ }^{17}$ which revealed that the two $\mathrm{Ca}^{2+}$ ions were bound to extremely well coordinating ion sites in the middle of the transmembrane domains.

When we studied "backdoor phosphorylation" of the Na,K-ATPase in the absence of $\mathrm{K}^{+}$ions, ${ }^{18}$ we found that the population of the state of $\mathrm{E}_{2}$ that could be phosphorylated by $\mathrm{P}_{\mathrm{i}}$ needed to have occluded two $\mathrm{H}^{+}$ions, so that the reaction sequence has to be:

$$
\mathrm{E}_{1}+2 \mathrm{H}^{+}{ }_{\text {cyt }} \rightarrow \mathrm{H}_{2} \mathrm{E}_{1} \rightarrow \mathrm{E}_{2}\left(\mathrm{H}_{2}\right) \rightarrow \mathrm{P}-\mathrm{E}_{2}\left(\mathrm{H}_{2}\right) \rightarrow \mathrm{P}-\mathrm{E}_{2}+2 \mathrm{H}^{+}{ }_{\text {ext }}
$$


Because of this finding it was important to investigate the interaction of $\mathrm{H}^{+}$ions with the ion-binding sites to scrutinize whether instantaneous $\mathrm{H}^{+}$binding to empty sites of the $\mathrm{Na}, \mathrm{K}$-ATPase in state $\mathrm{E}_{1}$ conceals otherwise electrogenic $\mathrm{Na}^{+}$and $\mathrm{K}^{+}$ movements.

\section{COMPETITION OF $\mathrm{H}^{+}$WITH $\mathrm{Na}^{+}$AND $\mathrm{K}^{+}$IONS AT THE CYTOPLASMIC SITES}

$\mathrm{Na}^{+}$binding in state $\mathrm{E}_{1}$ can be measured by equilibrium titration experiments with high accuracy using the fluorescent styryl dye RH421. ${ }^{13}$ This dye, and others of this family, are hydrophobic substances with one polar end, so they insert into lipid membranes in an aligned manner. ${ }^{19}$ Due to the electrochromic mechanism of their chromophore they detect changes of local electric fields in the membrane dielectric and, therefore, report charge movements in membrane preparations which are packed with ion pumps, such as $\mathrm{Na}, \mathrm{K}$-ATPase ${ }^{13,18}$ and SR Ca-ATPase. ${ }^{14,15}$ From $\mathrm{Na}^{+}$-titration experiments with the $\mathrm{Na}, \mathrm{K}$-ATPase in its $\mathrm{E}_{1}$ conformation the halfsaturating concentration, $K_{1 / 2}$, was determined by fitting a Hill function to the $\mathrm{Na}^{+}$dependent fluorescence changes. These experiments were performed in buffers with a $\mathrm{pH}$ set between 6 and 8.5. In FIGURE 2 the $K_{1 / 2}$ values obtained from such experiments are shown as function of $\mathrm{pH}$. They show clearly that binding of $\mathrm{Na}^{+}$is affected by $\mathrm{H}^{+}$ concentration. $K_{1 / 2}$ increases between $\mathrm{pH} 8.5$ and 6 by a factor of $5 . K_{1 / 2}$ corresponds approximately to the $K_{\mathrm{M}}$ value of the second of three $\mathrm{Na}^{+}$ions bound. ${ }^{13}$ The fluorescence change observed in these experiments was generated by the binding of the third $\mathrm{Na}^{+}$ion to the " $\mathrm{Na}^{+}$-specific site," 12,13 and it was found that the maximum fluores-

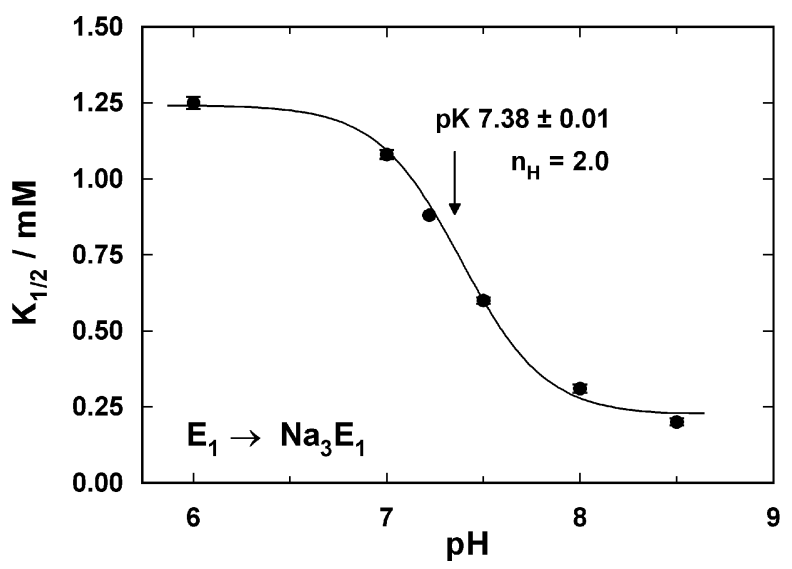

FIGURE 2. Effect of buffer $\mathrm{pH}$ on cytoplasmic $\mathrm{Na}^{+}$binding as detected by $\mathrm{RH} 421 \mathrm{flu}-$ orescence changes. Buffers contained $25 \mathrm{mM}$ histidine and $0.5 \mathrm{mM}$ EDTA, and $\mathrm{pH}$ was adjusted by Tris or $\mathrm{HCl}$. The half-saturating $\mathrm{Na}^{+}$concentration, $K_{1 / 2}$, increased with the $\mathrm{H}^{+}$ concentration, which can be explained by competition between $\mathrm{Na}^{+}$and $\mathrm{H}^{+}$at the same site(s). The drawn line through the data represents a fit with a Hill function with a halfsaturating concentration of $41.7 \mathrm{nM}$ (or $\mathrm{pK} 7.38$ ). 


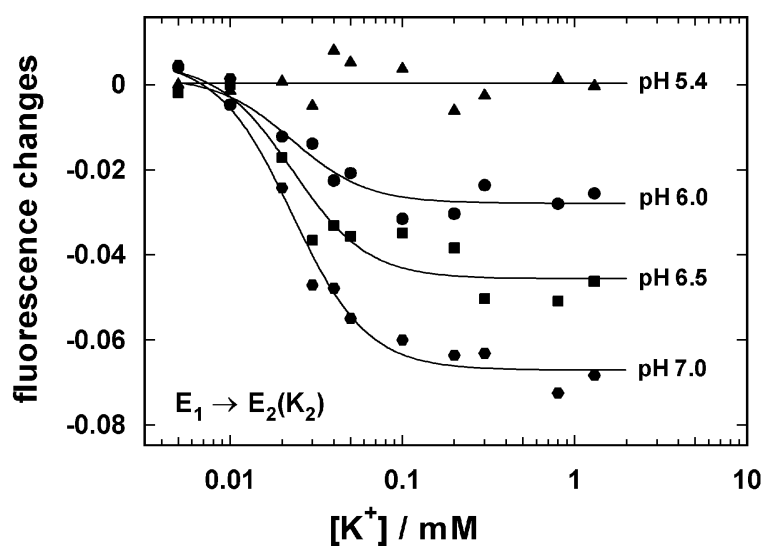

FIGURE 3. Cytoplasmic $\mathrm{K}^{+}$binding to the Na,K-ATPase detected by fluorescence changes of RH421 at various $\mathrm{pH}$ in a buffer containing $25 \mathrm{mM}$ histidine, and $0.5 \mathrm{mM}$ EDTA, when $\mathrm{pH}$ was adjusted by $\mathrm{HCl}$. Data were fitted with a Hill function (solid lines). The Hill coefficient of $2.0 \pm 0.1$ was constant over a $\mathrm{pH}$ range of 5.4-7.

cence change was not significantly affected by the $\mathrm{pH}$ applied (not shown). This indicates that no competition between $\mathrm{Na}^{+}$and $\mathrm{H}^{+}$occurred at the third binding site. Therefore, it may be proposed that $\mathrm{H}^{+}$is able to bind to side groups of amino acids which are part of (or close to) the two binding sites which are not $\mathrm{Na}^{+}$specific. If so, this should be reflected also in $\mathrm{pH}$ effects on $\mathrm{K}^{+}$binding, which shows barely significant electrogenic effects when investigated at physiological $\mathrm{pH}^{12,20}$ Results of $\mathrm{pH}-$ dependent cytoplasmic $\mathrm{K}^{+}$binding are shown in FIGURE 3. Although the fluorescence changes were much smaller than in the case of $\mathrm{Na}^{+}$binding, it is clear that electrogenic $\mathrm{K}^{+}$binding could be seen when the buffer $\mathrm{pH}$ was increased from 5 to 7 . The Hill fits drawn through the data had a Hill coefficient, $n_{\mathrm{H}}$, of 2 , which indicated interactions with more than one $\mathrm{H}^{+}$in this process. At $\mathrm{pH} 5.4$ no apparent or net charge movement could be detected. Experiments with buffer $\mathrm{pH}$ higher than 7 could be obtained only by addition of Tris, but this addition reduced the fluorescence changes for so far unknown reasons and these data were therefore not included in the analysis.

\section{CYTOPLASMIC AND EXTRACELLULAR H ${ }^{+}$BINDING}

$\mathrm{pH}$-titration experiments were performed in the absence of other monovalent cations in $\mathrm{E}_{1}$, and in P- $\mathrm{E}_{2}$ conformations of the Na,K-ATPase. The latter were obtained in the presence of $\mathrm{Mg}^{2+}$ ions either by addition of $500 \mu \mathrm{M} \mathrm{P}_{\mathrm{i}}$ or by addition of 10 $\mathrm{mM} \mathrm{NaCl}+100 \mu \mathrm{M}$ ATP. The $\mathrm{pH}$-induced fluorescence changes are shown in FIGURE 4. Although the fluorescence changes were small, when in the $\mathrm{E}_{1}$ conformation, $\mathrm{H}^{+}$ions were added in the $\mathrm{pH}$ range 7.2-5.5, these changes $(\Delta \mathrm{F}=-13 \%)$ were nevertheless significant. In control experiments with completely blocked enzyme $\Delta \mathrm{F}$ $<5 \%$ was found for the same $\mathrm{pH}$ jump. When the reaction sequence $\mathrm{E}_{1} \rightarrow \mathrm{H}_{2} \mathrm{E}_{1} \rightarrow$ $\mathrm{E}_{2}\left(\mathrm{H}_{2}\right)$ was studied during backdoor phosphorylation, ${ }^{18}$ a pK value of 8.6 was esti- 
mated from the $\mathrm{pH}$-dependent population of state $\mathrm{E}_{2}\left(\mathrm{H}_{2}\right)$, so that below $\mathrm{pH} 7.2$ more than $95 \%$ of the ion sites in $\mathrm{E}_{1}$ would have bound protons. Therefore it must be expected that further addition of $\mathrm{H}^{+}$would produce only minor fluorescence changes.

When the enzyme was phosphorylated, the fluorescence increased by between $30 \%(\mathrm{pH} 5.5)$ and $40 \%\left(\mathrm{pH} 7.2\right.$ ), indicating the release of at least one $\mathrm{H}^{+}$ion from inside the transmembrane region of the protein. This may be explained as a consequence of a dramatic decrease of the $\mathrm{pK}$ of one (or more) amino acid side groups to which the protons bind in the $\mathrm{E}_{1}$ conformation when no $\mathrm{Na}^{+}$or $\mathrm{K}^{+}$ions are present. Reducing the $\mathrm{pH}$ in state $\mathrm{P}-\mathrm{E}_{2}$ by addition of aliquots of $\mathrm{HCl}$ resulted in a decrease of the RH421 fluorescence, which represents $\mathrm{H}^{+}$binding to a site within the protein dielectric (FIG. 4). The obvious differences in the fluorescence levels in the two protein conformations may be explained by the above-mentioned large shift of the pK values of the side chains of acidic amino acids to which $\mathrm{H}^{+}$are able to bind in, or close to, the ion-binding sites. Thus, whereas in $\mathrm{E}_{1}$ the $\mathrm{pK}$ (about 8.6) is so high that in the physiological $\mathrm{pH}$ range the "sites" are mostly occupied by $\mathrm{H}^{+}$ions in the absence of other cations, the $\mathrm{pK}$ in $\mathrm{P}-\mathrm{E}_{2}$ is proposed to drop so significantly that the same sites are then largely unprotonated. A rough estimate from the titration experiment in FIGURE 4 suggests a $\mathrm{pK}<5.5$ for $\mathrm{P}-\mathrm{E}_{2}$.

\section{CONSEQUENCES FOR THE STRUCTURE-FUNCTION RELATIONSHIP}

On the basis of these results, together with the generally accepted constraint that all P-type ATPases have closely related structures, ${ }^{16}$ a concept for the position and characteristics of the ion-binding sites may be developed that is able to describe the

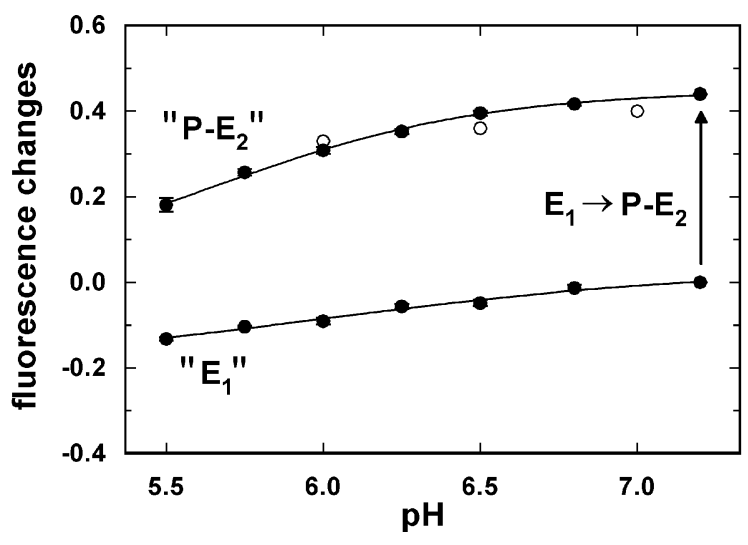

FIGURE 4. $\mathrm{pH}$ titration of the ion sites in the two principal conformations, $\mathrm{E}_{1}$ and $\mathrm{P}$ $\mathrm{E}_{2}$, in the absence of other monovalent cations. The vertical arrow indicates the RH421 fluorescence change induced by phosphorylation of the $\mathrm{Na}, \mathrm{K}$-ATPase with $\mathrm{P}_{\mathrm{i}}$ in the absence of other monovalent cations, or by addition of $10 \mathrm{mM} \mathrm{NaCl}+100 \mu \mathrm{M}$ ATP. Initial buffer composition was $25 \mathrm{mM}$ histidine, $0.5 \mathrm{mM}$ EDTA, and $10 \mathrm{mM} \mathrm{MgCl}_{2}$, at $\mathrm{pH}$ 7.2. 
electrogenicity as well as the detected interaction, or competition, of the cations binding to these sites. To maintain the homology of ion sites in the P-type ATPases, it is assumed that in the $\mathrm{E}_{1}$ conformation two sites are in the middle of the membrane dielectric, where they were recently identified for the SR Ca-ATPase. ${ }^{17}$ In the case of the $\mathrm{Na}, \mathrm{K}$-ATPase these sites are able to bind various monovalent cations ${ }^{21}$ including $\mathrm{H}^{+}$, as shown above. Binding of a third $\left(\mathrm{Na}^{+}\right)$ion, which is a special feature of the $\mathrm{Na}, \mathrm{K}-\mathrm{ATPase}$, occurs only after two $\mathrm{Na}^{+}$ions have already bound. ${ }^{21}$ This third site is positioned about $25 \%$ of the dielectric thickness into the membrane from the cytoplasmic side ${ }^{12}$ and is virtually exclusively selective for $\mathrm{Na}^{+}$. Such a topographical arrangement, however, appears to contradict the observation that the cytoplasmic binding or release of the two $\mathrm{K}^{+}$or of the first two $\mathrm{Na}^{+}$ions is not electrogenic. ${ }^{12,20}$ To resolve this problem, the reported $\mathrm{H}^{+}$binding to the cytoplasmic sites may be brought into play.

When under physiological conditions the $\mathrm{Na}, \mathrm{K}$-ATPase reaches state $\mathrm{K}_{2} \mathrm{E}_{1}$ in the pump's cycle, the subsequent release of $\mathrm{K}^{+}$ions may be accompanied (and supported) by an uptake of one $\mathrm{H}^{+}$per $\mathrm{K}^{+}$ion that binds to an acidic side group of an amino acid at the binding site: $\mathrm{K}_{2} \mathrm{E}_{1}+2 \mathrm{H}^{+} \rightarrow \mathrm{H}_{2} \mathrm{E}_{1}+2 \mathrm{~K}^{+}$. Such a reaction would be apparently electroneutral. Only at high $\mathrm{pH}$ approaching the $\mathrm{pK}$ of the $\mathrm{H}^{+}$binding groups, would a significant electrogenic contribution of $\mathrm{K}^{+}$binding and release become detectable (cf. FIG. 4).

A corresponding reaction is to be expected for binding of the first two $\mathrm{Na}^{+}$ions to $\mathrm{H}_{2} \mathrm{E}_{1}$. Moreover, any small effect of incompletely matched exchange of $\mathrm{Na}^{+}$for $\mathrm{H}^{+}$on the RH421 fluorescence at physiological $\mathrm{pH}$ would be concealed because binding of the third $\mathrm{Na}^{+}$is electrogenic and generates a large and $\mathrm{pH}$-independent contribution. Nevertheless, the competition between $\mathrm{Na}^{+}$and $\mathrm{H}^{+}$ions for the same sites is evident in the $\mathrm{pH}$ dependence of the half-saturating $\mathrm{Na}^{+}$concentration for binding of the first two $\mathrm{Na}^{+}$ions (FIG. 2). The fact that, despite the almost complete occupancy of the sites by $\mathrm{H}^{+}$under physiological conditions, $\mathrm{Na}^{+}$binding is so fast that it could not be resolved so far may be explained by the fact that $\mathrm{H}^{+}$ions are extremely small and can exchange between a carboxylate and a water molecule without steric hindrance for (or by) cation that is shedding off its hydration shell to enter the binding site. In addition, a multiply coordinated (alkali) cation and a "free" $\mathrm{H}_{3} \mathrm{O}^{+}$ ion are an energetically much more favorable combination than a free cation and a protonated carboxylate.

\section{CONCLUSIONS}

The placement of two ion-binding sites of the Na,K-ATPase inside of the membrane dielectric, as suggested by the structure of the SR Ca-ATPase and the apparent electroneutrality of cytoplasmic $\mathrm{K}^{+}$release and binding of the first two $\mathrm{Na}^{+}$ions under physiological conditions, can be explained by a transient binding of two $\mathrm{H}^{+}$ions to carboxylate groups in or close to the ion binding sites. This leads to a modification of the post-Albers cycle (cf. FIG. 1A) for the $\mathrm{E}_{1}$ conformation in the following way:

$$
\cdots \rightarrow \mathrm{K}_{2} \mathrm{E}_{1} \mathrm{ATP} \rightarrow \mathrm{H}_{2} \mathrm{E}_{1} \mathrm{ATP} \rightarrow \mathrm{Na}_{2} \mathrm{E}_{1} \mathrm{ATP} \rightarrow \mathrm{Na}_{3} \mathrm{E}_{1} \mathrm{ATP} \rightarrow \cdots
$$

After binding of two $\mathrm{Na}^{+}$ions in exchange for two $\mathrm{H}^{+}$ions the highly specific third site becomes available and the third $\mathrm{Na}^{+}$ion binds electrogenically. This non- 
single file mechanism allows the last ion bound to be released first after the conformation transition to the $\mathrm{P}-\mathrm{E}_{2}$ states. In $\mathrm{P}-\mathrm{E}_{2}$ the ion sites are modified such that they may have shifted slightly within the dielectric, but certainly such that the affinity for $\mathrm{Na}^{+}$and $\mathrm{H}^{+}$ions has decreased by orders of magnitude, whereas that for $\mathrm{K}^{+}$remains almost constant. ${ }^{10}$ Due to the low affinity of the binding sites for $\mathrm{H}^{+}$in $\mathrm{P}-\mathrm{E}_{2}$ under physiological conditions the sites remain unoccupied, and consequently release of $\mathrm{Na}^{+}$and binding of $\mathrm{K}^{+}$are found to be electrogenic.

\section{ACKNOWLEDGMENTS}

This work is based on collaborations with Milena Roudna and Anna Diller. This work was supported by the Deutsche Forschungsgemeinschaft (Ap 45/4) and INTAS 2001-0224.

\section{REFERENCES}

1. GLiTSCH, H.G. 2001. Electrophysiology of the sodium-potassium-ATPase in cardiac cells. Physiol. Rev. 81: 1791-1826.

2. JoRgensen, P.L. \& P.A. PEDERSEN. 2001. Structure-function relationships of $\mathrm{Na}^{+}, \mathrm{K}^{+}$, ATP, or $\mathrm{Mg}^{2+}$ binding and energy transduction in Na,K-ATPase. Biochim. Biophys. Acta 1505: $57-74$.

3. LÄUGER, P. 1991. Electrogenic Ion Pumps: 1-313. Sinauer. Sunderland, MA.

4. APELL, H.-J. 1997. Kinetic and energetic aspects of $\mathrm{Na}^{+} / \mathrm{K}^{+}$-transport cycle steps. Ann. N. Y. Acad. Sci. 834: 221-230.

5. Albers, R.W. 1967. Biochemical aspects of active transport. Annu. Rev. Biochem. 36: 727-756.

6. Post, R.L., C. Hegyvary \& S. Kume. 1972. Activation by adenosine triphosphate in the phosphorylation kinetics of sodium and potassium ion transport adenosine triphosphatase. J. Biol. Chem. 247: 6530-6540.

7. WUDDEL, I. \& H.-J. APELL. 1995. Electrogenicity of the sodium transport pathway in the Na,K-ATPase probed by charge-pulse experiments. Biophys. J. 69: 909-921.

8. Holmgren, M. et al. 2000. Three distinct and sequential steps in the release of sodium ions by the $\mathrm{Na}^{+} / \mathrm{K}^{+}$-ATPase. Nature 403: 898-901.

9. DE WEER, P., D.C. GADSBY \& R.F. RAKOWSKI. 2000. The Na/K-ATPase: a current-generating enzyme. In The Na/K Pump and Related ATPases. K. Taniguchi \& S. Kaya, Eds.: 27-34. Elsevier. Amsterdam.

10. ApEll, H.J. \& S.J. KaRLish. 2001. Functional properties of Na,K-ATPase, and their structural implications, as detected with biophysical techniques. J. Membr. Biol. 180: $1-9$.

11. HilgemanN, D.W. 1994. Channel-like function of the Na,K pump probed at microsecond resolution in giant membrane patches. Science 263: 1429-1432.

12. DomaszewiCZ, W. \& H.-J. APELL. 1999. Binding of the third $\mathrm{Na}^{+}$ion to the cytoplasmic side of the Na,K-ATPase is electrogenic. FEBS Lett. 458: 241-246.

13. SCHNEEBERGER, A. \& H.-J. APELL. 1999. Ion selectivity of the cytoplasmic binding sites of the Na,K-ATPase: I. Sodium binding is associated with a conformational rearrangement. J. Membr. Biol. 168: 221-228.

14. BuTSCHER, C., M. RoudNA \& H.-J. APELL. 1999. Electrogenic partial reactions of the SR-Ca-ATPase investigated by a fluorescence method. J. Membr. Biol. 168: 169-181.

15. Peinelt, C. \& H.-J. APELl. 2002. Kinetics of the $\mathrm{Ca}^{2+}, \mathrm{H}^{+}$and $\mathrm{Mg}^{2+}$ interaction with the ion-binding sites of the SR-Ca-ATPase. Biophys. J. 82: 170-181.

16. SwEAdNER, K.J. \& C. DONNET. 2001. Structural similarities of Na,K-ATPase and SERCA, the $\mathrm{Ca}^{2+}$-ATPase of the sarcoplasmic reticulum. Biochem. J. 356: 685-704. 
17. Toyoshima, C. et al. 2000. Crystal structure of the calcium pump of sarcoplasmatic reticulum at $2.6 \AA$ resolution. Nature 405: $647-655$.

18. APELL, H.-J. et al. 1996. Kinetics of the phosphorylation of Na,K-ATPase by inorganic phosphate detected by a fluorescence method. Biochemistry 35: 10922-10930.

19. PEDERSEN, M. et al. 2001. Detection of charge movements in ion pumps by a family of styryl dyes. J. Membr. Biol. 185: 221-236.

20. PinTSCHOVIUS, J., K. FENDLER \& E. BAMBERG. 1999. Charge translocation by the $\mathrm{Na}^{+}$ $\mathrm{K}^{+}$-ATPase investigated on solid supported membranes: cytoplasmic cation binding and release. Biophys. J. 76: 827-836.

21. SCHNEEBERGER, A. \& H.-J. APELL. 2001. Ion selectivity of the cytoplasmic binding sites of the Na,K-ATPase: II. Competition of various cations. J. Membr. Biol. 179: 263-273. 